\title{
Ante un segundo ciclo de la posdictadura...
}

\author{
2 ANALÍA Gerbaudo / Universidad Nacional del Litoral - CONICET \\ agerbaudo@fhuc.unl.edu.ar; analia.gerbaudo@conicet.gov.ar
}
El pasado es este presente en el que lo que dejamos impreso es la parte equivalente a lo que se deja escapar. HORACIO GONZÁLEZ, «Mito e historia», La biblioteca

Con el eco de las distinciones williamsianas entre lo «residual», lo «emergente» y lo «dominante», Horacio González subraya «las distintas formas del tiempo existentes en toda realidad histórica» (2008:8): presente, pasado y futuro se anudan «de un modo más opaco de lo que llegó a percibir el presidente Alfonsín cuando, en una de sus alocuciones durante las asonadas militares que entrecortaron su período, propuso: "por un momento una ráfaga del pasado nos ha rozado"» (8). Su insistencia machacona en estas convivencias insinúa el carácter simplificador de cualquier corte temporal que pretendiera alisar bajo rótulos englobantes momentos complejos de nuestra cultura que suponen "formas de vida» en conflicto. Porque la pregunta de González respecto de si la democracia supone «una forma de vida» (7), trae consigo una impronta afirmativa que no aplaca la atención a lo incompleto, a lo que resta y a lo "por-venir» (Derrida 2002, Kofman y Dick 2003, 2005). ${ }^{1}$

A los efectos de no banalizar se imponen, entonces, ciertas prevenciones: lejos tanto de la petulancia como del voluntarismo, se periodiza para ayudar a re-flexionar, para contribuir a resaltar el carácter superfluo de "toda hipótesis de marcha» identificada con un estado de las cosas conquistado "para siempre» y/o sin restos, sin vestigios, sin emergencias «monstruosas», sin fisuras. Como bien observa González, cuando se hablaba del pasaje de «la anomalía dictatorial a la democracia recobrada» se trazaba «un arco que calcaba los modelos ejemplares de tránsito cultural, desde la oscuridad a la razón y desde la barbarie a las luces civilizatorias» (8). Por efecto mágico, la historia «se repartía en dos y comprendía en el hemisferio recobrado todo lo que uniformemente pertenecía a la vida buena, plausible» (8) y, en el otro, a ese pasado horroroso que se pretendía 
dejar para siempre atrás (Nunca más, el título del informe presentado por la Comisión Nacional sobre la Desaparición de personas (CONADEP) al presidente Raúl Alfonsín el 20 de setiembre de 1984, expresa también ese deseo, imperioso y sintomático, de delusorio cierre definitivo).

Con matices diferentes, algunos investigadores (cf. Antelo, Gerbaudo, Schwarzböck) oponemos a este tipo de relatos otro «que nos comprenda como sujetos de la propia historicidad que esos mismos actos crean» (González 2012:37) sin dejar de atender a las convivencias que Raymond Williams ha conceptualizado con sutileza y que, desde otro lugar, Jacques Derrida ayuda a pensar cada vez que recuerda la condición, en parte ficcional, de todo "origen», de toda demarcación que se pretenda nítida, sin porosidades.

Desde esta concepción del "tiempo agujereado», como diría David Viñas (I986), señalamos dos ciclos de la posdictadura. Ciclos con correlato en diferentes momentos establecidos a partir de la irrupción de «acontecimientos» (Derrida 2003a, 2003 b) que, como tales, desbaratan lo imaginado para el futuro inmediato en el país. Si en textos anteriores justificábamos por qué llamábamos "posdictadura" al período comprendido entre 1984 y 2003, hoy necesitamos interrogar si no fue aquello un primer ciclo de la posdictadura al que le sigue otro. Un segundo ciclo que comenzaría junto con las decisiones tomadas desde el gobierno que ocupa el Estado a partir de diciembre de 2015 y que suponen retrocesos en derechos humanos, laborales, educación, salud, ciencia, tecnología, comunicación, relaciones internacionales, economía, seguridad, etc.: vuelven a abrirse las heridas nunca del todo cicatrizadas dejadas tanto por el terrorismo de Estado como por decisiones que, aún bajo el orden democrático, continuaban las políticas económicas, culturales y simbólicas de la dictadura. Contra estos retrocesos, enmarcados en un plan estratégico que sería ingenuo confundir con intimidatorios episodios aislados, son emblemáticas algunas reacciones populares. Citamos las que atraviesan más directamente nuestras prácticas profesionales: la instalación frente al Congreso de la Nación en abril de 2017 de la Escuela Itinerante para expresar el rechazo a los recortes en educación (una forma de manifestar que recuerda la Carpa Blanca de los ańos noventa, emplazada en el mismo lugar); el lavado público de platos por los científicos del CONICET tras la aprobación del presupuesto 2017 para el sector (una evocación de la descalificación, unida a los recortes a la ciencia y a la tecnología, promovida por el ministro de economía Domingo Cavallo, también durante los años noventa); la marcha del io de mayo de 2017 para protestar ante la sanción del «2 por I» por la Corte Suprema de justicia que implica un inquietante retroceso en los avances obtenidos gracias a la lucha por los derechos humanos; la marcha del viernes in de agosto reclamando por la «aparición con vida» de Santiago Maldonado, desaparecido durante la represión encarnada por la Gendarmería Nacional a una protesta liderada por la comunidad mapuche en el sur del país.

Se advertirá, entonces, por qué es imperioso cuidar el modo de nombrar: se pretende devolverle espesor a un tiempo transido por huellas de otros. Se pretende 
explicitar por qué, lamentablemente, fue sólo un gesto bien-intencionado rotular Nunca más al informe de la CONADEP. Como José Rabasa cuando esgrime sus razones para hablar de "poscolonialismo", es necesario aclarar que el prefijo "pos» llama la atención sobre «las continuidades y legados» (220) entre un momento y otro: no es, de ninguna manera, la simple referencia a lo que viene después.

A pesar de este estado de las cosas, queremos cerrar esta editorial con un hecho auspicioso, aunque de otra escala (esa escala «nano» que sostenemos como nuestro principal lugar de intervención): se trata de la incorporación de Fernando Degiovanni, Juan Ennis, Bénédicte Vauthier, Sara Bosoer, Valeria Sager y Alejandra Laera al Comité Científico de nuestra revista. Además de darles la bienvenida, aprovechamos la ocasión para, otra vez, hacer extensivo el agradecimiento a los colegas que cooperan con la evaluación de artículos: sin ese trabajo gratuito, sencillamente no sería posible sostener este proyecto colectivo, este espacio conjunto de construcción de pensamiento en un campo intelectual marcadamente heterónomo que, otra vez, tenemos que salir a defender contra intromisiones proferidas desde los poderes religioso, mediático, empresarial y estatal. Está en juego, junto con la educación y la ciencia por las que luchamos, el concepto de vida posible. Está en juego, entonces, la vida misma.

\section{Notas}

1 «Por-venir» no es un término equivalente a «futuro». La «democracia por-venir» es a los sistemas democráticos lo que la "justicia» es al «derecho» (Derrida 1994): una meta que permite no descansar en la «buena conciencia del deber cumplido» para atender a lo que falta así como a las cristalizaciones que inmovilizan, que impiden parpadear (cf. Derrida 1983). Cuando Jacques Derrida «solicita» los conceptos de «democracia»,

«razón» $\mathrm{y}$ «mundo», lo que interroga va mucho más allá del lenguaje o de un hacer disciplinar o de un conjunto mayor como las «humanidades»: es otro pensamiento de lo posible (de la vida posible) lo que esta interpelación impulsa. Un pensamiento que hace lugar a lo aún no imaginado, a lo no previsible, a lo fuera de cálculo, al acontecimiento (con las derivas políticas y éticas que estos planteos suponen).

\section{Bibliografía}

ANTELO, RAÚL (20I6). «Programa para un posgrado futuro». El taco en la brea 3, I44-17I. Web. DERRIDA, JACQUES (1983). «Les pupilles de l'Université. Leprincipe de raison et l'idée de

l'Université». Du droit à la philosophie. París: Galilée, 1990, 46I-498.

(1994). Fuerza de ley. El «fundamento místico de la autoridad». Madrid: Tecnos, 1996. Traducción de Adolfo Barberá y Patricio Peñalver Gómez. - (2002). «La raison du plus fort (Y-a-t-il des États voyous?)». Voyous. Deux essais sur

la raison. París: Galilée, 2003, 25-16I. (2003a). Genèses, généalogies, genres et le génie. Les secrets de l'archive. París: Galilée. (2003b). «Auto-immunités, suicides réelset symboliques. Un dialogue avec 
Jacques Derrida», «La déconstruction du concept du terrorisme selon Derrida», en Giovanna

Borradori, editora. Le «concept» du II septembre. Dialogues à New York (octobre décembre 200I).

París: Galilée, I33-244.

gerbaudo, analía (2016). Politicas de exhumación. Las clases de los críticos en la universidad argentina de la posdictadura (1984-1986). Santa Fe/Los Polvorines: UnL/Ungs.

GONZÁLEZ, HORACIO (2008). El peronismo fuera de las fuentes. Buenos Aires: UNGS/BN.

(2012). Lengua del ultraje, de la generación del 37 a David Viñas. Buenos Aires: Colihue. KofMAN, AMY ZIERING Y KIRBy Dick (2003). Derrida. Ee. UU.: Zeitgeist films/Jane Doe films Production.

(2005). Derrida. Screenplay and Essays on the film. Manchester: Manchester University Press.

RABASA, JOSÉ (2009). "Poscolonialismo», en Mónica Szurmuk y Robert MckeeIrwin, coordinadores. Diccionario de Estudios Culturales Latinoamericanos. México: Siglo xxi/ Instituto Mora, 219-223.

sCHWARZBöcK, silvia (20I6). Los espantos. Estética y postdictadura. Buenos Aires: Cuarenta Ríos (Las cuarenta y El río sin orillas).

VIÑAS, DAVID (1986). Clases. «Literatura argentina». Buenos Aires: Facultad de Filosofía y Letras, UBA. Investigación CIC-CONICET. CD-ROM.

williams, RaYmond (1977). Marxismo y literatura. Barcelona: Península, 1980. Traducción de

Pablo Di Masso. 